\title{
E SPORT: APLICATIVO MOBILE DE INTERAÇÃO ESPORTIVA
}

\author{
QUEIROZ, Adilson Junio Barreto ${ }^{1}$ \\ MARIANO, Igor Cunha ${ }^{2}$ \\ LEMES, Kaynnan Bardauil ${ }^{3}$ \\ RIBEIRO JÚNIOR, Leonardo da Silva ${ }^{4}$ \\ QUEIROZ, Paulo Henrique Silva ${ }^{5}$ \\ PESSOA, Marcelo ${ }^{6}$ - iDttps://orcid.org/0000-0002-9193-4604
}

RESUMO: Este texto apresenta os resultados parciais de um trabalho interdisciplinar realizado por alunos da Graduação do curso de Bacharelado em Sistemas de Informação, da Universidade do Estado de Minas Gerais, Unidade Frutal. A situação-problema que orientou o Grupo de Trabalho (GT), foi a de preencher a lacuna de interação e comunicação existente entre os praticantes de esportes da cidade de Frutal - MG. Por meio de um levantamento preliminar, via consulta informal aos praticantes de esportes de Frutal, o GT percebeu que a comunicação entre esta comunidade de interesse poderia ser melhorada. Assim, o GT propôs o desenvolvimento de um aplicativo mobile, que pudesse viabilizar a comunicação e a construção de redes interativas que envolvessem os esportistas da cidade.

PALAVRAS-CHAVE: Aplicação mobile, interação social, esportistas.

ABSTRACT: This text presents the partial results of an interdisciplinary work carried out by undergraduate students of the Bachelor's degree in Information Systems, University of the State of Minas Gerais, Frutal Unit. The problem situation that guided the Working Group (GT), was to fill the gap of interaction and communication existing among sports practitioners in the city of Frutal - MG. Through a preliminary survey, through informal consultation with Frutal sports practitioners, the WG realized that communication between this community of interest could be improved.Thus, the GT proposed the development of a mobile application, which could make possible the communication and the construction of interactive networks involving the sportsmen of the city.

KEYWORDS: Mobile application, social interaction, sportsmen

\footnotetext{
${ }^{1}$ Discente do Curso de Bacharelado em Sistemas de Informação, UEMG - Unidade Frutal.

${ }^{2}$ Discente do Curso de Bacharelado em Sistemas de Informação, UEMG - Unidade Frutal.

${ }^{3}$ Discente do Curso de Bacharelado em Sistemas de Informação, UEMG - Unidade Frutal.

${ }^{4}$ Discente do Curso de Bacharelado em Sistemas de Informação, UEMG - Unidade Frutal.

${ }^{5}$ Discente do Curso de Bacharelado em Sistemas de Informação, UEMG - Unidade Frutal.

${ }^{6}$ Docente e Orientador no Curso de Bacharelado em Sistemas de Informação, UEMG - Unidade Frutal.
} 


\section{INTRODUÇÃO}

O presente texto trata de apresentar os resultados parciais do trabalho interdisciplinar realizado por um grupo de alunos do Curso de Bacharelado em Sistemas de Informação, da Universidade do Estado de Minas Gerais, Unidade Frutal.

O grupo discente se reuniu e propôs, como objetivo, a criação de um aplicativo mobile para a área esportiva. Desse modo, o produto que foi gerado consiste na criação de um programa, cuja finalidade principal é a de reunir indivíduos e dinamizar a comunicação daqueles que tenham interesses semelhantes voltados à prática de esportes.

Justificou a realização de um trabalho como este, o fato de que, nos dias de hoje, as pessoas que gostam de esportes estão em busca de se integrarem a grupos físicos e virtuais para que possam ampliar o leque de amigos com interesses comuns.

Uma das situações-problema que deveriam ser resolvidas pela equipe, era a de que nem todas as pessoas que praticam esportes têm "coragem" de se aproximar de outros praticantes para perguntar sobre seus gostos, para começar uma amizade ou mesmo para combinar horários de práticas esportivas em comum.

O aplicativo foi elaborado na plataforma "Kodular", ambiente virtual próprio para o desenvolvimento de aplicativos para o sistema "Android".

A partir daí, instituiu-se uma interface que fosse dotada de um alto valor de contribuição aos usuários, especialmente quanto à facilidade de encontrar grupos com interesses semelhantes, que possibilitasse comunicação rápida, e que fosse de fácil interação para os usuários que têm dificuldades para se comunicar com outras pessoas. 


\section{DESENVOLVIMENTO}

Desse modo, constatou-se que alguns alunos do quarto ano do curso de Bacharelado em Sistemas de Informação estavam desenvolvendo um trabalho sobre startups.

Um dos integrantes daquele Grupo de Trabalho apresentou ao nosso Grupo de Trabalho um esboço sobre a criação de uma aplicação direcionada aos praticantes de esportes. Assim, como esse aluno do quarto ano é irmão de um dos integrantes do presente grupo, e que também pratica esportes, surgiu a ideia de auxilia-los na criação de um aplicativo. E, a partir disso, foi criado o Documento de Requisitos.

Dito isso, a parte da engenharia de software foi feita em uma plataforma chamada "Kodular", visto que ela se relaciona com aplicativos "Android". Dando um primeiro passo para o desenvolvimento, começamos a fazer a primeira tela (tela principal) que é composta pelos elementos: E-mail, senha, um design voltado para a ideia principal desse projeto, o nome do aplicativo, a opção de entrar, criar conta e recuperar senha.

Essas opções foram criadas em conjunto, para, assim, deixar a primeira tela feita e pronta, pois, a partir dela, o trabalho ficaria mais complicado.

Após isso, a barra de menu lateral foi criada, dando um acesso inicial para o uso de nosso banco de dados, o qual será melhor aproveitado posteriormente. Depois disso, foi arrumado no aplicativo os elementos do "menu", os quais serão utilizados, assim como o cadastro dos usuários com o banco de dados.

Nesse estágio do aplicativo, a primeira letra do CRUD estava feita, sendo ela o C (creat). Seguindo mais a fundo no aplicativo e passando para a parte do $\mathrm{R}$ (read), o banco de dados foi explorado para que, assim, as funções pudessem ser utilizadas, mexendo com códigos em PHP, fazendo a ponte entre o banco de dados utilizado, "MySQL", e o "Kodular".

Faltaria, agora, apenas o término do design do aplicativo, visando deixa-lo leve e visualmente agradável, mantendo o contato entre cores, desenhos e o tema proposto. 
O desafio com mais ênfase foi 0 de criar um chat para cada grupo e conversas em privado, mantendo o contexto escolhido e privacidade para aqueles que assim desejarem.

$\mathrm{Na}$ fase de testes, o programa foi executado com o objetivo de encontrar erros e inconsistências em relação à proposta do aplicativo, observando se há bugs, se foram esquecidos alguns procedimentos no cadastro, login, tela e nas outras opções propostas no Documento de Requisitos do aplicativo.

Após a execução de testes do aplicativo, pudemos notar que o design estava sem relação com a proposta e com o logo do aplicativo. Este elemento foi modificado, assim, para que fosse visivelmente melhor ajustado à percepção visual em situação real de interação. Notamos, também, que parte da tela inicial estava colidindo com barra de rolagem, a qual foi também modificada para que no aplicativo "rodasse" melhor.

\section{RESULTADOS E DISCUSSÕES}

RF1: O sistema deve permitir a inclusão, alteração, exclusão e recuperação dos clientes, contendo os seguintes atributos: nome, e-mail único, telefone, data de nascimento e a sua senha desejada.

RN1.1: Todos os campos acima são obrigatórios.

RF2: O aplicativo terá apenas os administradores dos grupos (os que criarão o seu grupo), os que serão responsáveis para a inclusão, exclusão dos membros.

RN2.1: Os membros poderão modificar e excluir seu próprio perfil.

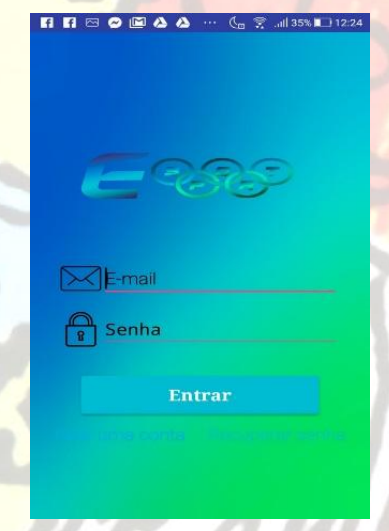


Essa é a tela inicial do aplicativo, contendo os itens: E-mail, Senha, Entrar, Recuperar Senha e Cadastrar-se. Momento em que notamos que aqui poderia ser a tela que o usuário irá logar, se cadastrar (caso seja a opção, irá ser redirecionado para outra tela) e para aqueles que esquecerem sua senha, recuperá-la.

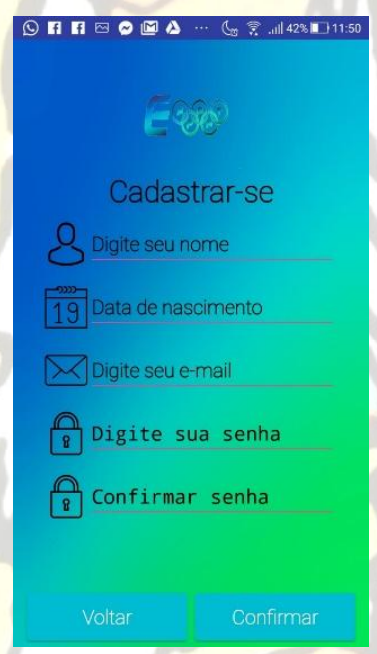

Essa é a tela que o usuário entrará quando clicar em "cadastrar-se", aqui tem as lacunas para digitar o nome, data de nascimento, e-mail e a senha com um campo para confirmação. Esses passos serão os responsáveis para que o usuário possa usufruir da aplicação.

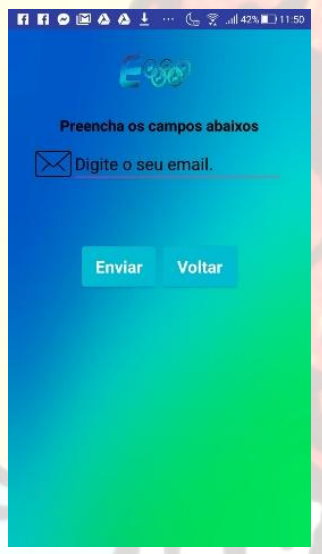

Essa será a tela que o usuário irá encontrar ao clicar na opção de recuperar senha. Preenchendo o que for pedido, logo a baixo irá aparecer a sua nova senha. 


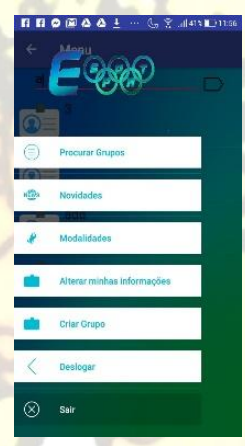

Esse é o menu lateral, sendo uma opção já dentro do Aplicativo, ali podemos ver todas as opções do usuário, tudo que o App pode te proporcionar.
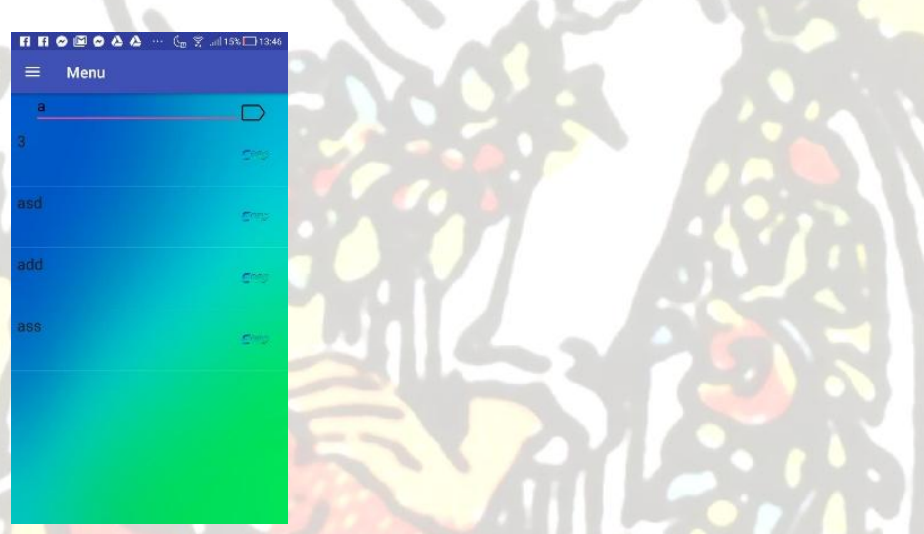

Essa é a primeira tela que o usuário verá ao efetuar o login, aqui ele irá começar a pesquisar os grupos que ele tem interesse, assim aproveitando o que o aplicativo proporciona.

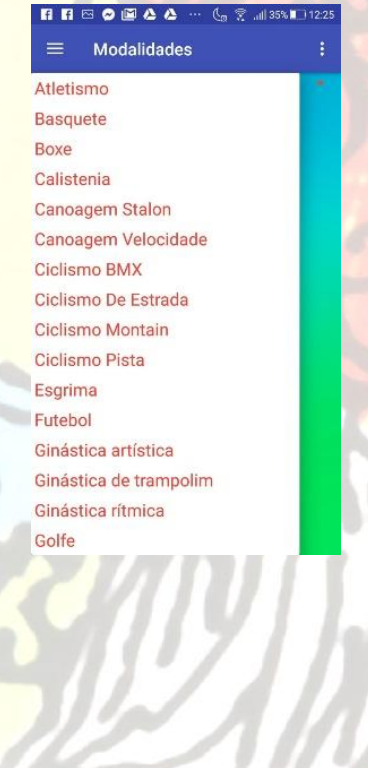

Revista AKEDIA - Versões, Negligências e Outros Mundos $p$ - ISSN 2447-7656 e-ISSN 2674-2561 DOI 10.33726 - Vol. 8 - Ano V - 2o Sem. 2019 
Nesse local, podemos ver e escolher as modalidades que 0 aplicativo proporciona, deixando que o usuário ache mais facilmente aquilo que ele desejar.

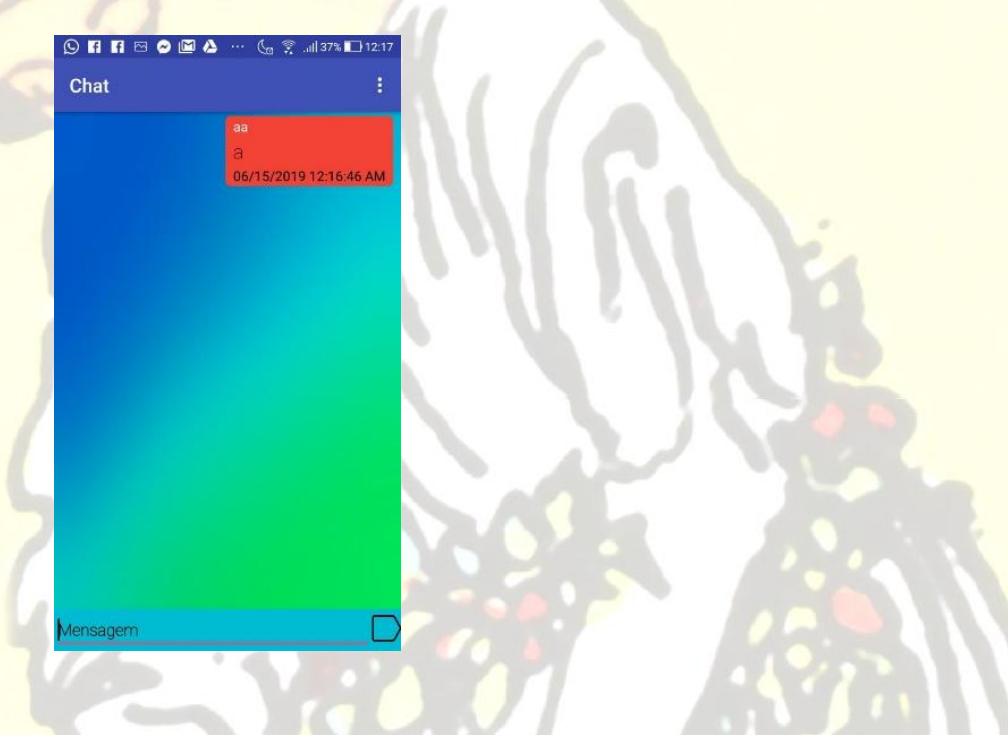

Já dentro do grupo, essa é a tela que o usuário vai encontrar, sendo aqui o chat para proporcionado pelo aplicativo, permitindo que o "ambiente" esportivo seja mantido.

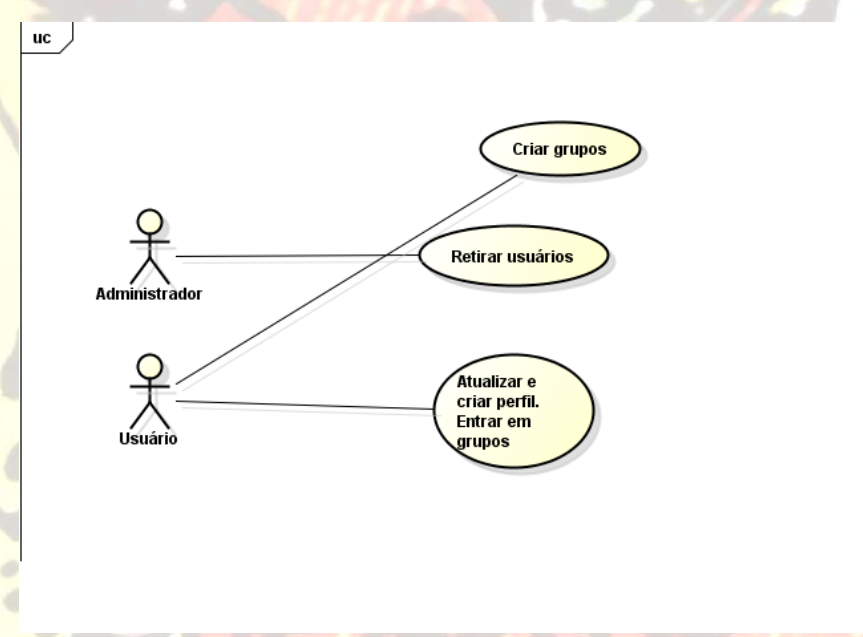

me

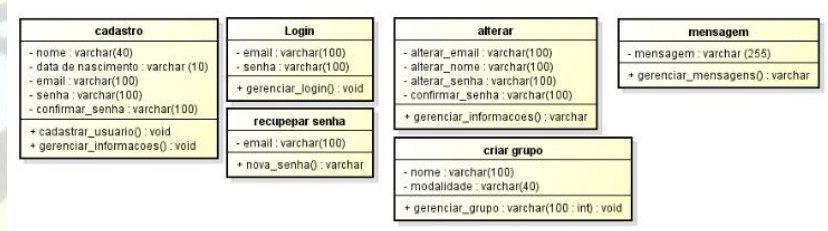

Revista AKEDIA - Versões, Negligências e Outros Mundos $p$ - ISSN 2447-7656 e-ISSN 2674-2561 DOI 10.33726 - Vol. 8-Ano V-2o Sem. 2019 


\section{CONSIDERAÇÕES FINAIS}

O presente projeto foi desenvolvido com o intuito de ajudar os amantes de esportes a se enturmarem com outros esportistas.

A utilização do "Kodular", num primeiro momento, deu-se, devido à objetividade encontrada para utilizar a plataforma, ainda que esta fosse apenas a primeira etapa do projeto.

A partir daqui seria feito em "React Native". O PHP foi utilizado ao invés do "Firebase", em função de sua originalidade, sendo que "Firebase" armazena em seu servidor próprio ("GOOGLE"), e o PHP nos permite armazenar em nosso próprio banco de dados, assim mantendo nossa "marca".

O "MySQL" foi usado por já termos obtido conhecimento prévio nas salas de aula. Além de manter a interdisciplinaridade no projeto, mantendo uma plataforma mobile, uma linguagem de programação e o banco de dados já explicado em sala.

O aplicativo foi criado para fazer o registro de grupos de esportes para que pessoas que tenham interesses comuns possam interagir com outros com os demais integrantes do grupo, deixando que cada um possa criar sua conta, alterar seus dados, ver novidades, conversar e pesquisar modalidades dentro do APP.

Para os próximos anos do desenvolvimento do aplicativo, passaremos esse projeto inicial para a linguagem "JAVA SCRIPT", utilizando "React Native" por ter um melhor desenvolvimento e melhor execução.

O aplicativo pode ser encontrado para download no seguinte link: https://bit.ly/2KmoldL

\section{REFERÊNCIAS}

ATSPACE. ATSPACE.COM. Disponível em: https://www.atspace.com/ 2019. Acesso em: 17 de jun de 2019.

MAKEROID. KODULAR, 2019. Disponível em: https://www.kodular.io/ 2019. Acesso em: 17 de jun de 2019.

PORTARI, S. C. DESENVOLVIMENTO MOBILE. Disponível em: http://www.sergioportari.com.br/index.php/aulas/2019-2/uemg-frutal /desenvolvimento-mobile-optativa/. Acesso em: 11 de jun. de 2019. 